\title{
La Técnica Académica en el Cuerpo Latinoamericano
}

The Academic Technique in the Latin American Corps

Emilia Fierro Ciriza ${ }^{1}$

UNIVERSIDAD ACADEMIA HUMANISMO CRISTIANO

Resumen. A partir de la reflexión sobre las estrategias a las que recurren profesores y estudiantes universitarios de danza para enseñar y aprender técnica académica en cuerpos latinoamericanos, se indaga en la comprensión consciente e inconsciente de ciertos abordajes pedagógicos de la técnica académica que buscan superar la distancia que relaciona dos realidades históricas y culturales diferentes: la técnica académica y el cuerpo latinoamericano. Mediante un recorrido histórico y el análisis de los factores influyentes recopilados en entrevistas a profesores y estudiantes, se logra identificar temas fundamentales a abordar en la simbiosis de dichos elementos que parecen, en ocasiones, tan distantes entre sí y que intervienen en el desarrollo de la técnica académica universitaria. La consideración en la sala de clases de los factores recopilados en las entrevistas da luces sobre una nueva concepción de la técnica académica que se está llevando a cabo en las aulas. Se construye una nueva mirada que pone en cuestión la unificación y homogenización y que da cabida a la diversidad como principal característica identitaria latinoamericana. Finalmente, esta apertura a la modificación de los parámetros rígidos determinantes de la técnica académica en pro de la diversidad constituye una manifestación de resistencia sociopolítica, en tanto responde al cuestionamiento de imposiciones externas a sus identidades latinoamericanas.

Palabras clave. Pedagogía en Danza; Cuerpos Latinoamericanos; Técnica Académica; Sincretismo; Identidad.

\begin{abstract}
Based on the reflection on the strategies used by university dance teachers and students to teach and learn academic technique in Latin American bodies, it investigates the conscious and unconscious understanding of certain pedagogical approaches to academic technique that seek to overcome the distance that relates two different historical and cultural realities: academic technique and the Latin American body. Through a historical journey and the analysis of the influencing factors collected in interviews with teachers and students, it is possible to identify fundamental issues to be addressed in the symbiosis of these elements that seem, at times, so distant from each other and that they intervene in the development of the university academic technique. The consideration in the classroom of the factors collected in the interviews sheds light on a new conception of academic technique that is being carried out in the classrooms. A new look is being built that calls into question the unification and homogenization and that makes room for diversity as the main Latin American identity characteristic. Finally, this openness to modifying the rigid determining parameters of academic technique in favor of diversity constitutes a manifestation of sociopolitical resistance, as it responds to the questioning of external impositions to their Latin American identities.
\end{abstract}

Key Words. Dance Pedagogy; Latin American; Bodies; Academic Technique; Syncretism; Identity.

\footnotetext{
${ }^{1}$ Licenciada en Danza, Magister en Liderazgo Transformacional. Universidad Academia Humanismo Cristiano. Mail: emilia.fierro@uacademia.cl.
} 


\section{Introducción}

Para comenzar el tema de la técnica académica en el cuerpo latinoaméricano es preciso viajar en el tiempo cientos de años atrás y situarse en el territorio prehispánico latinoamericano. Cuando los conquistadores españoles llegaron al territorio que posteriormente se conocería como Centroamérica, estos se encontraron con una gran diversidad de culturas prehispánicas, con una particular manera de desarrollar su vida cotidiana, relaciones humanas, métodos de supervivencia, su coexistencia con la naturaleza, entre otras prácticas que aportaban al gran entramado cultural de este nuevo mundo. Dichas construcciones sociales humanas estaban regidas principalmente por la funcionalidad, de acuerdo a sus necesidades básicas y cosmovisión. El grado de desarrollo de un grupo humano respondería a la capacidad de este para subsistir en el entorno habitado y a su habilidad de sortear las complejidades que este, u otro grupo humano, le significara. De esta manera, se generó la existencia conjunta de innumerables clanes, grupos, tribus, familias y/o bandas nómadas o sedentarias que poblaron el vasto territorio continental. Naturalmente, por temas de dominancia territorial y/o ideológica, ciertos grupos humanos crecieron y sometieron a otros más pequeños, lo que significó una masificación de sus organizaciones y desencadenó en lo que hoy son estudiadas como civilizaciones o imperios (Silva 18-20).

Todos estos datos dan cuenta de un panorama diverso extendido por todo el territorio latinoaméricano. Estas diferencias se dan a todo nivel. En general, las que llaman la atención de los estudiosos tienen que ver con la organización social o las creencias. Sin embargo, la diversidad se plasma también en otros aspectos del ser humano, como las formas de relacionarse, sentir o moverse; aspectos poco explorados que podrían agruparse bajo la idea de cuerpo. De un lado a otro del continente era y es posible encontrar diferencias sustanciales entre los cuerpos, las que respondían al quehacer de los sujetos de acuerdo al lugar en el que se encontraban, su ocupación diaria, el clima que les acompañaba, su alimentación y geografía, entre otros. Por ejemplo, el cuerpo de los habitantes del territorio centro altiplánico del continente distaba mucho del de los habitantes de la Patagonia, el cual, a su vez, se diferenciaba del de los habitantes del Imperio maya.

Desde la conquista española, la variedad intentó ser reemplazada por unificación. Sobre un territorio diverso en culturas, cae el peso ineludible de una cultura dominante. La cultura europea llega al nuevo continente con un fin claro: civilizar a los incivilizados, adiestrar a los salvajes, unificar lo diverso. En los planes de la conquista española estaban los objetivos de dominar el territorio de manera absoluta; crear reinados de la Corona española y convertir a los indígenas al catolicismo. Los conquistadores llegaron al territorio, lo exploraron y se apropiaron de sus riquezas. Lo que antes la naturaleza proporcionaba a las culturas prehispánicas, ahora debía ser extraído por los salvajes, y entregado en su totalidad a la Corona española. Las sociedades existentes deben acoplarse a lo entendido por la sociedad europea. Los territorios, pertenecientes por siglos a grupos asentados en ellos, ahora deben ser decidos a los conquistadores. Toda creencia distinta al único Dios católico debía ser abolida, con lo que se instauran los conceptos de pecado y moral. Ante todo esto, los conquistados tenían dos opciones: asimilaban y apropiaban la instrucción de la Corona española, o bien, eran eliminados. Los conquistadores no consideraban como válida la opción de algo distinto a lo traído por ellos.

Se impone a los indígenas prehispánicos una lengua común: el castellano. Una corporalidad diferente: cubierta, pudorosa, pecadora, recatada y señorial. El territorio que era suyo, ya no le es propio. 
Así, se impone también una forma de arte distinto: se cierra el espacio a manifestaciones artísticas divinas hacia la naturaleza, se prohíben los rituales. Los códigos dancísticos han cambiado, pues ahora solo se baila en parejas en una relación distante, de acuerdo a la moral imperante.

Este último punto supone un factor fundamental en el estudio a realizarse. Con la instalación de los europeos en América, se comienza a sectorizar la cultura a una ocupación casual, lo que quebra de raíz la relación cotidiana ritual que los indígenas prehispánicos habían establecido con las manifestaciones artísticas. Poco a poco, lo que hasta 1492 se conocía como realidad en el territorio abordado comienza a variar, a mezclarse, a teñirse de otros colores, a adoptar nuevas culturas y a transformarse en una cultura cuyo sincretismo continuará a lo largo de los siglos.

Hoy en día, pasados más de 500 años de aquel entonces, nos situamos en América Latina, en un país llamado Chile, independizado de la Corona española hace apenas 210 años, en cuya cultura es posible encontrar los frutos de las semillas sembradas durante la colonización. Pese a que el objetivo de la conquista europea era unificar pensamiento, tradiciones, religiones, estilos de vida y cuerpos, la respuesta del poblado prehispánico ha sido una especie de resistencia hacia lo nuevo. Transcurrido el tiempo, la diversidad en el territorio se ha ramificado en todos los aspectos de la vida, lo que llena el continente de una incalculable y compleja heterogeneidad, posible de ser encontrada cada día en cada rincón de América Latina: idiomas, gastronomías, ocupaciones, edificaciones, vestimentas, relaciones humanas, artes, políticas, religiones, creencias y cuerpos se han mezclado; han generado sincretismo y han otorgado al mapa un sinfín de colores. Si se observa cada rincón del continente en la actualidad, muy probablemente, se diferencie en alguno, si no en todos, los aspectos de su rincón opuesto.

La cultura significó un eje importante en cuanto a la resistencia de parte de los conquistados frente a lo nuevo, pues la fusión entre las manifestaciones artísticas existentes previamente en el territorio latinoamericano y las influencias externas recibidas han dado como resultado una nutrida variedad y calidad a la cultura moderna latinoamericana, al punto de ser reconocida y respetada a lo largo de todo el planeta. En la música, las artes visuales, artes escénicas, danzas tradicionales, entre otras, es posible encontrar mixturas de tradición con influencias europeas e incluso africanas y/u orientales. Aunque se intentó unificar a la población, Latinoamérica continúa siendo muchos tipos de cuerpos en un mismo continente. Siguen existiendo aquí muchas creencias, lenguas, historias y culturas en un mismo pedazo de tierra. En ese aspecto, la danza en general, como expresión humana, ha sido capaz de acoger la transmisión de costumbres sincreticamente. A lo largo del tiempo, la manifestación dancística ha respondido a los factores de cambios históricos, sociales e incluso políticos, lo que genera nuevos lenguajes y amplía más aún la gama diversa de las expresiones artísticas. Hasta hoy en día continuamos siendo muchas danzas en un continente y muchos cuerpos intentando aprender cada danza.

Sin embargo, dentro de la enseñanza de la danza, existe un elemento que continúa abordando la herencia europea de manera bastante estricta y rígida en cuanto a lo que sincretismo refiere: el ballet. Esta manifestación artística representa, en su origen, la unificación traída por los conquistadores. Se muestra al público como un elemento llamativo, con su belleza, delicadeza y elegancia. Su rimbombancia expresiva, su virtuosismo y su destreza son significantes implícitos de la superioridad que el europeo traía desde el otro lado del mar. Y se enseña como tal. El cuerpo apropiado es largo, esbelto, longilíneo, liviano y ágil. La estructura también es una; todo viene previamente establecido y escrito; solo puede variar el orden de los factores, pero no el producto en sí. En una sala, todo es formaciones espaciales correctas y ordenadas. Líneas, filas, cuadrados, círculos, todo equidistante. Lo uniforme, como tal, uniforma (del latín uniformis: de forma única). 
Hoy en día, las normas bajo las que se enseña el ballet en la mayoría de los casos (a través de la técnica académica) son casi las mismas de hace siglos atrás. Los profesores entregan al estudiante una serie de conocimientos universalmente reconocidos y practicados de igual manera. Así, la técnica académica enseñada en Chile es en esencia la misma que la enseñada en España, Francia, Alemania, Brasil, etc., con leves variaciones (o no) en la metodología. Como tal, los requerimientos físicos serán los mismos. Es decir, a un cuerpo latinoamericano, se le exigirá lo mismo que a uno europeo, independiente de los factores evidentemente diferentes entre sí.

Como todo lo traído por los conquistadores europeos al territorio del nuevo continente, el ballet también se entrega con la imposición de su única manera de funcionamiento, en un cuerpo que, como también se comentó, es diverso por esencia. De esta manera, surgen las siguientes preguntas: ¿qué estrategias se usan para enseñar y aprender, en cuerpos diversos, una técnica que ha sido creada para un solo cuerpo? ¿Cómo enseñamos en Chile y América Latina el ballet? ¿Podemos hacer caso omiso a la variedad de cuerpos y enseñar una verdad única trascendente a un solo cuerpo? Por lo anterior, el objetivo que guía el presente artículo es analizar las estrategias de enseñanza y aprendizaje de la técnica académica en cuerpos latinoamericanos a las que recurren profesores y estudiantes universitarios de danza. He ahí la dificultad que lleva a las preguntas del presente artículo.

\section{Cuerpo/identidad latinoamericana}

Desde siempre, el tema de la identidad en América Latina ha sido un factor convocante de diversos puntos de vista, investigaciones y discusiones. Y no es para menos, pues se trata de un continente cuya herencia procede de una larga historia de llegadas, partidas, encuentros, desencuentros, mezclas, ires y venires. Podría decirse, sin conjeturar, que en el territorio latinoamericano confluyen trozos de historia de todos los lugares del mundo. Son todas estas historias y sucesos los que determinan la disputa a la hora de cimentar el concepto de identidad. Al respecto, jugarse por una sola carta parece una apuesta riesgosa. Comúnmente, en toda sociedad se busca comprender la identidad como un concepto singular, cuando, a sabiendas de lo anteriormente mencionado, dista mucho de serlo. Por tanto, se abarcará el concepto de manera más amplia y realista: se hablará de las identidades (Vergara y Vergara 86-90).

Las identidades son un elemento de constante cambio y no pueden, por ello, ser determinadas de una manera hermética e invariable. Sin embargo, hay teorías que consideran la variabilidad constante del tema, por lo que disponen algunos trazos que pueden ayudar a inclinarse por una postura específica al respecto. En esta ocasión, se tratarán cuatro tesis, muy diferentes una de la otra, que plantean un punto de vista determinante respecto del problema de la identidad en Latinoamérica y que han sido recabadas y comparadas por Vergara y Vergara (79-80).

La tesis que se tratará en primer lugar plantea desde el comienzo una paradoja: la identidad latinoamericana no es latinoamericana, sino más bien, indígena. Se postula que la llegada y dominación de la cultura europea no comprende más que una yuxtaposición en todos los sentidos que abarca la cultura, lo que crea una apariencia de modernidad, que, en su esencia, jamás ha dejado de ser indígena. Dicha tesis, llamada indianista, ha tomado fuerza en diversos países de Latinoamérica, especialmente en Perú y Bolivia, donde se han creado incluso movimientos políticos y culturales de envergadura, con miras a cambiar radicalmente la visión de sociedad y retomar la forma de organización social prehispánica (Vergara y Vergara 80-81). 
Por contraposición extrema, la tesis hispanista expone que Latinoamérica es completamente heredera de la cultura hispana. En ella se postula que los indígenas vivían en estado de naturaleza, que la conquista fue de carácter espiritual y evangelizador y que, desde entonces, no existieron colonias, sino solo provincias del Imperio español. También menciona que los españoles fundaron naciones, y que la independencia significó para América solo la separación política de España. En la mirada de los hispanistas, por tanto, Latinoamérica siempre ha sido por esencia hispana y continúa hasta el día de hoy siéndolo (Vergara y Vergara 81-82).

Una tercera tesis plantea que Latinoamérica es (o está en vías de ser) una sociedad occidental. Dicha tesis, denominada tesis occidentalista, se basa en el contraste con sociedades no occidentales, como Asia o África. A diferencia de dichas sociedades, América Latina ya no posee culturas tradicionales vigentes cuyas costumbres se diferencien en su totalidad de lo occidental. Esto se debe a que el largo proceso de colonización y luego el periodo republicano terminaron por occidentalizar en su totalidad el territorio, lo que transformó la sociedad latinoamericana y todos sus componentes en una reproducción de Europa (Vergara y Vergara 82-84).

Por último, la tesis del mestizaje cultural sugiere que la identidad y la cultura de Latinoamérica son resultado de diversos elementos provenientes de los pueblos prehispánicos en síntesis con elementos de Europa y África. Como consecuencia de dicha integración, se crea una visión ante el mundo característica de América Latina. La tesis de mestizaje cultural, que se plantea hoy en día como la más difundida y aceptada, tiene sus orígenes en el pensamiento bolivariano. Sin embargo, se puede decir que se oficializa en manos de José Vasconcelos, escritor mexicano, en el libro La raza cósmica (1924) (Vergara y Vergara 84-85).

Como es posible notar, cada tesis difiere notablemente de la otra y aporta desde una perspectiva distinta a las demás, aunque no excluyentemente. Independiente de su postura radical, por ejemplo en el caso de las tesis indianista e hispanista, no se niega en ningún caso que la intervención del otro -influencia europea o pasado indígena- existe, y continúa siendo latente. Entonces, el punto común de todas estas tesis termina siendo el mismo: Latinoamérica es una porción del planeta que surge de una amalgama cultural, sea desde donde sea que se mire.

Siglos después de la Conquista, en la transición entre XIX y XX, el panorama no varía mucho en cuanto al conflicto latino-europeo. A pesar de que muchas naciones del territorio se independizaron políticamente, Europa continúa siendo el referente principal de organización sociopolítica a seguir. En dicha época, se desarrollan en América Latina planes de modernización cultural, cuyo fruto resuena como un eco desgastado de la realidad europea (García Canclini 8184).

A lo largo del tiempo, el latinoamericano ha caído y recaído en la ilusión de una realidad mejor; un símil europeo capaz de generar el estilo de vida deseado por toda persona. Sin embargo, en América Latina se continúa a la siga de un modelo que en lo económico, lo social, lo cultural, lo político y lo cotidiano demuestra un desarrollo mucho mayor. En este incansable afán, muchas veces se reniega de la condición mestiza del territorio, pues el sueño del latino, en su mayoría, no es adoptar el ritmo de vida europeo, sino más bien ser Europa, dejando a un lado el evidente acontecer de su realidad híbrida. Como menciona García Canclini:

Los países latinoamericanos son actualmente resultado de la sedimentación, yuxtaposición y entrecruzamiento de tradiciones indígenas (sobre todo en las áreas mesoamericana y andina), del hispanismo colonial católico y de las acciones 
políticas, educativas y comunicacionales modernas. Pese a los intentos de dar a la cultura de elite un perfil moderno, recluyendo lo indígena y lo colonial en sectores populares, un mestizaje interclasista ha generado formaciones híbridas en todos los estratos sociales $(86)$.

Respecto del cuerpo y la identidad, mucho hay que decir, pues el cuerpo presenta una peculiar relación recíproca causa-consecuencia: resulta como consecuencia de un proceso históricoidentitario, y, a su vez, deviene causa de este. América Latina goza de un cuerpo rico en historia, al que el tiempo no le pasa en vano; un cuerpo que es muchos cuerpos. La antropóloga colombiana Zandra Pedraza (159-160) sitúa al cuerpo como núcleo de la condición humana, y por ende, del suceso histórico. A diferencia del pensamiento común científico, en el que se separa el cuerpo de la mente (ciencias humanistas versus ciencias biológicas), Pedraza propone el punto de vista de la antropología histórica, donde la existencia humana se comprende como un hecho corporal y sensorial simultáneo. Como tal, y por consecuencia, el tema se liga con lo histórico identitario, pues:

...el cuerpo ha tendido a convertirse en un recurso primordial para construir y exponer la identidad, actividades, estas dos, que se influencian recíprocamente pues el vínculo entre cuerpo e identidad compromete en el caso de América Latina intereses de orden político nacional expresados en los esfuerzos culturales hechos para modelar la condición humana entorno de maniobras conjuntas de saber y poder... (Pedraza 159-160).

He aquí entonces la reiteración del tema. Una vez más queda comprobado que la identidad latinoamericana se forja a partir de una diversidad de factores $\mathrm{y}$, por consecuencia, denota una identidad diversa, más bien, muchas identidades. Existe un factor común al comprender latinoamericano: la resistencia ante lo homogéneo. Y es justamente por ello que no podemos entender el cuerpo latinoamericano como uno solo, más bien, una diversidad de cuerpos basados en un supuesto, pero cada cual exquisito en su particularidad.

\section{Técnica académica}

Para adentrarse en el tema de fondo, es necesario mantener la idea -ya argumentada y justificadade un cuerpo latinoamericano diverso, heterogéneo, múltiple, mestizo, híbrido, lejano a la existencia de un parámetro común o, dicho de otra manera, de la normalidad. Un cuerpo que escapa a la uniformidad y lo establecido y que, tal como se mencionaba anteriormente, ha transitado por una historia, no exento de modificaciones. A través del tiempo, el cuerpo del latinoamericano ha 
sido objeto de múltiples intervenciones, violentas o pasivas, a voluntad o impuestas, conscientes e inconscientes, que, de manera inevitable, han forjado un conflicto interno $-\mathrm{y}$ muchas veces externo- que viene a cuestionar precisamente la diversidad corporal. La invasión europea a la América prehispánica buscó transformar y/o suprimir las concepciones de cuerpo hasta ese entonces comprendida por los invadidos.

Al respecto, la danza no se queda atrás. La técnica académica surge justamente en un contexto muy distante de la diversidad corporal latinoamericana. Sin embargo, no es posible crear el nexo sin contextualizar primeramente los orígenes del ballet. Los inicios de la técnica académica se remontan a Europa en épocas del siglo XV y siglo XVI. Si bien se conocen variadas teorías sobre el origen del ballet, la que toma más fuerza siempre es aquella que señala su nacimiento en Francia, específicamente en el siglo XVI, bajo el alero de la nobleza de las cortes reales, razón por la cual se le llama ballet de cour, o ballet de corte (Esteban 9).

Sin embargo, es necesario comprender que existe una diferencia entre el ballet y la técnica académica. Es importante también recalcar que ambas nomenclaturas no siguen caminos separados, muy por el contrario, se entrecruzan y complementan de manera fundamental, pues una no existe sin la otra. En este caso, se indaga mayormente en el nacimiento de la técnica académica. Tal como menciona Esteban en Ballet, nacimiento de un arte, la aparición de la técnica académica ocurre en el territorio conocido en la actualidad como Italia, en épocas del Renacimiento. Ahí se concentraban una serie de estados y repúblicas, gobernados por distintas realezas, las que para competir por ostentación organizaban lujosas mascaradas, desfiles por las calles de la ciudad, en las que participaba toda la población. Nobles y señores poblaban la región, lo que mantenía en la población un constante ánimo de dominio entre sí (Esteban 17-18).

En un comienzo, la organización de los carnavales sucedía de manera espontánea, pero, con el pasar del tiempo y el asentamiento de la tradición, la coordinación fue siendo necesaria en función de engrandecer aún más el espectáculo, y así, el nombre del reinado organizador. Para ello, cada reinado contrataba los servicios organizativos de personas puntuales, quienes más adelante se convertirían en los primeros maestros de danzas y ballet. En dichas reuniones y carnavales de carácter festivo, el objetivo principal del maestro de ballet era, a través de la coreografía, enaltecer la imagen del gobernador y mostrarlo como una figura semi divina e inamovible. Para tal efecto, el plato fuerte de los eventos eran las representaciones artísticas, acompañadas de danzas, poesía y teatro, en las cuales la realeza interpretaba roles protagónicos. Así, tal como detalla Esteban, comenzó a considerarse la danza como eje fundamental de la vida sociopolítica, pues a través de esta, los espectáculos eran más majestuosos; la figura del gobernador se enaltecía por sobre su oponente, lo que entregaba al reinado un status que aumentaba sus posibilidades de expansión sobre el territorio enemigo. De esta manera, la figura del maestro de ballet comenzó a ser indispensable, pues de él dependía la imagen pública del gobernante y sus aliados activos en el reinado (Esteban 20).

En dicho intercambio cultural entre reinados y países, se asienta definitivamente la existencia de esta manifestación artística social. La naciente burguesía también la reconoce como tal y comienza a requerir de sus servicios en bodas, celebraciones, fiestas, nacimientos, etc. Con influencia italiana y francesa, la figura del maestro de ballet toma fuerza y se conforma, a medida de que su labor se hace más específica y transita lentamente desde la coreografía hasta llegar a la pedagogía. Particularmente en Francia, comienzan a surgir ciertos pasos y movimientos específicos que se repiten como patrón en la mayoría de los ballets de cour, movimientos que hasta el día de hoy, con ciertas modificaciones, se enseñan en clases de técnica académica en todo el mundo.

A través de los años, el ballet y la técnica académica comienzan a evolucionar, y a expandirse a lo largo de toda Europa y llegó a ser una forma artística de gran influencia. Como tal, 
se crean en diversos lugares y contextos, variados tratados, obras escritas y manuscritos, que van dando cuenta de cómo se generan convenciones universales de lo que vamos entendiendo como técnica académica, y su consecuencia escénica, el ballet (Esteban 53 - 58). El año 1658 se crea la Comunidad de Maestros de Danza, bajo el alero de unas cartas patentes del rey, quienes otorgaban el permiso a quien quisiera ser maestro de danza y/o bailarín y cumpliera con todos los requisitos (haber cursado entre tres y seis años la enseñanza exclusiva con otro maestro; aprobar los exámenes; saber tocar violín u otro instrumento y pagar una gran suma de dinero) (Esteban 112114). Con el correr del tiempo, la evolución de la técnica académica no sugiere muchos cambios de su expresión original, más bien ofrece a los bailarines y docentes mayor complejidad dentro de lo mismo. Por tanto, la metodología de enseñanza base de la técnica académica es, en su molde, la misma en todos los lugares del mundo en los que se enseña, con leves variaciones casi de orden estético en algunos casos. Dicho de otra manera, el diccionario de técnica académica continúa considerando los mismos movimientos acordados en sus inicios, solo que estos aumentan su complejidad en pro de incrementar el virtuosismo de bailarinas y bailarines.

¿Cómo se logra esto? La técnica académica, a grandes rasgos, trabaja con el uso de la postura rígida en el torso, en combinación con movimientos virtuosos de extremidades. Como resultado, el bailarín es capaz de ejecutar grandes destrezas. Para ello, la técnica académica busca, en su tradición, trabajar cuerpos desde la infancia, en lo posible, seleccionar niñas y niños estilizados, de extremidades largas, pies, piernas y espaldas flexibles, y aptitudes físicas y técnicas acordes al lenguaje.

Si se vuelve al tema anterior, la técnica académica, entonces, se comprende como una disciplina que busca el virtuosismo físico y kinético a través del trabajo progresivo y constante con rigidez postural. Es posible, de esta manera, generar un nexo directo con lo anteriormente expuesto, pues la verdad sobre la que se sostiene esta técnica es una: cuerpo largo, espalda recta, hombros y caderas alineadas, evitar la fuerza de gravedad, articulación coxofemoral rotada externamente, brazos ligeros, piernas altas y ágiles, rodillas estiradas, cuello alargado, cabeza liviana, entre otras indicaciones que son ley. De esta manera, y con estos parámetros, es desarrollada la técnica académica en su cuna europea. La causa y consecuencia de dicha técnica es una serie de cuerpos que se mueven y se ven homogéneos, que reproducen al unísono movimientos cuya perfección busca la uniformidad entre sus ejecutantes. De esa misma manera también, al igual que muchas otras cosas, es traída a Latinoamérica y enseñada en miles de cuerpos que quieren bailar. Cuerpos que, por lo demás, son diversos.

En un momento de la historia, y por largo tiempo, el ballet fue, junto con las danzas folclóricas, el único lenguaje dancístico reconocido y mostrado en teatros. Sin embargo, con el correr del tiempo y los sucesos históricos, la humanidad por respuesta a sus conflictos, fue generando espacios de creación de otros lenguajes corporales, los que tomaron fuerza y hoy en día se reconocen como parte de la expresión artística denominada danza. A pesar de esto, el ballet mantiene sus tradiciones y no modifica su quehacer basado en los parámetros originarios. De esta manera, hoy en día es posible escuchar muy a menudo que la técnica académica, en comparación con otros lenguajes, es rígida o cerrada. Esta impresión se justifica porque, a pesar de que la sociedad ha avanzado, cambiado y se ha transformado con el correr de los siglos, el ballet y la técnica académica continúan siendo una puerta al pasado.

La técnica académica se apoya en su historia y tradición, a partir de esto busca homogenizar a sus estudiantes; sistema que en escuelas de Europa desarrolla excelentes resultados, pues ahí es posible ver bailarines y bailarinas de dominio técnico incuestionable. Sin embargo, todo ello funciona en un contexto muy particular, con condiciones específicas: a los bailarines de los grandes 
ballets de Europa se les educa en la técnica académica a partir de los siete u ocho años (e incluso a veces antes) y, para ello, se realiza una serie de audiciones donde de cientos de postulantes, solo quedan los diez o veinte con mejores condiciones innatas. La carrera dura alrededor de ocho años y contempla jornadas de cinco días a la semana con tres a cuatro horas de entrenamiento en técnica académica y posteriores tres horas de ensayo relacionados al repertorio clásico. Según palabras de la investigadora argentina Ana Sabrina Mora:

El carácter de la técnica clásica hace que se considere necesario iniciar su aprendizaje desde la infancia, y mediando la preexistencia de determinadas condiciones físicas, dada la creencia en que no solo no todos los cuerpos corresponden a su ideal estético, sino que no todos los cuerpos son aptos para incorporar acabadamente su técnica; de todos modos, el carácter determinante que se atribuye a las condiciones no quita que se entienda al entrenamiento como la base para convertirse en bailarina o bailarín. La danza clásica plantea un trabajo a largo plazo: por medio del entrenamiento lento, graduado, sistemático, metódico, en el que cada paso dado se apoya en el logro de uno anterior, se va incorporando la técnica. Existe un proceso encadenado de etapas que no se deben saltar y que todos deben transitar; los resultados no se ven inmediatamente y esto exige regularidad y sentido de la disciplina. (Mora 327).

Entonces, ¿qué ocurre cuando se inserta esta disciplina en un contexto de cuerpo diverso como Latinoamérica, bajo condiciones muy diferentes a las europeas? La búsqueda de homogeneidad originaria del ballet tiene entonces un cuestionamiento claro. Puesto que en América Latina existe una gran diversidad corporal y social, es complejo abordar una técnica originariamente unificadora.

\section{Cuerpo, identidad, danza y pedagogía}

Hasta el momento se ha abordado recientemente temas de diversidad social, procesos históricos, danza clásica y pedagogía. Al respecto de la última, vale la pena preguntarse: ¿de qué manera se pueden organizar procesos pedagógicos que contemplen todo lo expuesto anteriormente? ¿Cómo se desarrolla la pedagogía considerando los procesos sociales y culturales de un determinado grupo de personas? A lo largo de los tiempos, la pedagogía tradicional ha comprendido al estudiante como un recipiente vacío, al cual el profesor debe llenar de la información que, según programas de estudio, planificaciones o criterios consensuados, es pertinente que este adquiera. Esto genera un 
distanciamiento en la relación profesor-estudiante y, a su vez, una jerarquización de conocimiento, en la cual el estudiante se asume como carente de conocimiento, por lo que el aprendizaje adquirido se comprende como la verdad absoluta y única. Por su parte, en este modelo pedagógico, el profesor reproduce conocimientos para que el estudiante los absorba, sin generar una discusión o mayor desarrollo del contenido.

En el siglo XX, se comienza a gestar la base de una rama de la pedagogía, denominada pedagogía crítica, que rompe con los esquemas de la pedagogía tradicional, lo que pone en jaque los roles profesor-estudiante-escuela y cuestiona la trascendencia de los contenidos pedagógicos. En la pedagogía crítica se busca que el estudiante se transforme en un elemento social activo y crítico. Bajo estos parámetros, se presenta al individuo como un actor social que crea, y a su vez es creado por la sociedad (McLaren 264-268).

Otro eje fundamental en la comprensión de la pedagogía crítica es la noción de la humanización de los procesos educativos. Al respecto, Ramírez Bravo señala que:

En este contexto, humanizar la educación no se reduce a procesos de instrucción, sino que también exige la reflexión, el análisis y el discernimiento de las propias actitudes y valores; reclama la confrontación del propio actuar con el actuar del otro para mejorar, no para censurar, excluir o descalificar (Ramírez 111)

La pedagogía crítica pretende crear un vínculo entre la educación y el devenir sociopolítico cultural del contexto en el que se desarrolla. De esta manera, la educación incide en formar individuos críticos en su pensamiento, capaces de analizar, discutir y cuestionar los asuntos de aprendizaje, y por tanto, de ser un elemento activo en el acontecer social de su entorno. Más allá del elemento político en el que se crea la pedagogía crítica, los factores sociales y culturales también toman peso a la hora de abordarlas desde un punto de vista más neutral. Esto es, comprender el conocimiento y las capacidades de un individuo como elemento transgresor, capaz de armar ruido (González 83 -85). A través del conocimiento, el individuo es capaz de debatir al respecto de cualquier tema y obtener siempre un aprendizaje de ello.

Muy distinto al enfoque tradicional, en la pedagogía crítica, el profesor, por su parte, se entrega a la experiencia pedagógica como un ente regulador entre el conocimiento y el estudiante, con retroalimentación de ambas partes. Al respecto, Paulo Freire señala:

...Es preciso [...] que desde los comienzos del proceso vaya quedando cada vez más claro que, aunque diferentes entre sí, quien forma se forma y re-forma al formar y quien es formado se forma y forma al ser formado. Es en este sentido como enseñar no es transferir conocimientos, contenidos, ni formar es la acción por la cual un sujeto creador da forma, estilo o alma a un cuerpo indeciso y adaptado. (Freire 25). 
A partir de esta breve noción de la pedagogía crítica, se ha considerado ciertos puntos fundamentales para vincularla a la pedagogía en la técnica académica: la noción de micro y macro objetivos en los programas de enseñanza, la integración entre teoría y práctica y, por último, la noción de la educación como resistencia.

Peter McLaren, en su texto La vida en las escuelas, hace referencia a la división del material educacional en dos grandes ramas:

1. Micro objetivos: contemplan los contenidos de un curso, planificación, materia, etc. En ellos no se tiene mayor posibilidad de cuestionamiento, pues son concretos y definidos. En palabras propias de McLaren: "los micro objetivos tienen que ver con la organización, la clasificación, el dominio y la manipulación de los datos” (McLaren 266). Por ejemplo, en la asignatura de Historia se enseñan los presidentes que han gobernado un país y la fecha correspondiente a su gobierno. Dichos datos corresponden a micro objetivos.

2. Macro objetivos: por su parte, los macro objetivos consideran las relaciones más a fondo que se pueden hacer con el aprendizaje de los contenidos. En el ejemplo anterior, la presencia de macro objetivos en la enseñanza se podría manifestar en que los profesores generen la instancia de discusión sobre qué situaciones socio políticas derivaron en que ese presidente llegara al mandato, qué reformas o cambios realizó y cómo estos modificaron de alguna u otra manera la estructura social del país, entre otras posibilidades. De esta manera, se crea un vínculo entre lo aprendido y el acontecer socio político cultural en el que los estudiantes se encuentran.

Al tener claros estos dos parámetros de organización de contenidos, es posible entonces que el estudiante dialogue, considerando ambas partes, pues los micro objetivos le serán útiles a la hora de organizar y comprender el conocimiento que los macro objetivos le han llevado a apropiar de manera profunda y analítica. Esto, a su vez, genera el vínculo necesario del aprendizaje educativo con la sociedad en la que el individuo se desenvuelve y así evitar que lo aprendido signifique una burbuja aislada, meramente teórica de la vida cotidiana (McLaren 266-267).

De esto último deviene el siguiente tema de importancia: la integración entre teoría y práctica.

...este escrito aboga por la naturaleza integradora de la pedagogía crítica en lo referente a la teoría y la práctica, pues es un artificio separarlas como si una derivara de la otra, obviando su argumento central al respecto, a saber, la reflexión no separa de la realidad ni la realidad de la reflexión. (Gómez y Gómez 182).

Muy comúnmente, se tiende a creer que la teoría y la práctica suceden como entes separados, o muy poco relacionados entre sí. Sin embargo, la enseñanza debe nutrirse de práctica y teoría de manera análoga, a fin de que ambos aprendizajes generen uno solo, perenne, sólido y consistente en su particularidad. Con esto último se hace referencia a lo siguiente: el educando 
podrá apropiar un conocimiento de manera mucho más eficaz si tanto práctica como teóricamente es capaz de asociarlo con su propia particularidad individual.

Es pensando críticamente la práctica de hoy o la de ayer como se puede mejorar la próxima. El propio discurso teórico, necesario a la reflexión crítica, tiene que ser de tal manera concreto que casi se confunda con la práctica. Su distanciamiento epistemológico de la práctica en cuanto objeto de su análisis debe ‘aproximarlo’ a ella al máximo. Cuanto mejor realice esta operación mayor entendimiento gana de la práctica en análisis y mayor comunicabilidad ejerce en torno a la superación de la ingenuidad por el rigor. (Freire 40).

Por último, pero no anexo a todo lo anterior, es necesario escarbar en la resistencia como eje fundamental de la pedagogía crítica, y así ligar el tema con todo lo anteriormente mencionado. La incorporación de las artes y la danza como elemento activo en la educación comprende un hecho fundamental en la acción de complementar la pedagogía con áreas de apoyo de material educativo. Las artes devienen del suceso humano, por tanto, aportan a la pedagogía un factor veraz a la hora de construir en el educando una consciencia crítica y constructiva respecto al ser humano y sus necesidades. El autor Javier Abad se refiere al tema en el libro Educación artística, cultura y ciudadanía:

... las artes son favorecedoras de dinámicas de integración escolar, social y cultural, mediante propuestas relacionadas con el fomento de actitudes para la tolerancia, la solidaridad y la convivencia creativa que promuevan una conciencia crítica frente a los mecanismos de exclusión social, y convertirse, a la larga, en un proceso consciente de crecimiento individual y colectivo. Todo lo anteriormente citado son ejemplos de respuestas a las demandas actuales que plantean la exigencia de imaginar procesos sociales y educativos diferentes, en los que la educación artística puede realizar importantes aportaciones en todo tipo de contextos humanos, como espacio de reflexión crítica y también como territorio para el intercambio y la 
promoción del otro como portador de innovación, riqueza y diversidad (con relación a la construcción de una identidad compartida, siempre en continuo tránsito, que no debe entenderse como competitividad, sino como colaboración en la proximidad) (19).

El arte como medio de resistencia, en complemento con la educación, fomenta la reflexión crítica a partir del acontecer sensible y/o emocional del estudiante. Desencadena, por consecuencia, un resultado constructivo del aprendizaje en directa relación con el individuo como ser único y particular en un contexto en el que este figura como un elemento activo. Puede, por tanto, resultar del suceso pedagógico en vínculo directo con el arte una resistencia frente a los temas de trascendencia que afecten al individuo o grupo de personas. Tal como menciona Pilar Díez del Corral:

Los autores de la Pedagogía Crítica vinculan el proyecto educativo al ámbito de la comunidad en la que se inscribe. Parten de un planteamiento y una reflexión constante de los hechos sociales, culturales y políticos de más trascendencia, y toman postura ante los actos de discriminación, injusticia o violencia. La pedagogía crítica desde la perspectiva comunicativa desarrolla el compromiso con el proceso socio histórico de profesores y estudiantes y fundamenta la posibilidad de cambio individual y social a partir de un proceso educativo basado en la interacción entre iguales (85).

Es importante resumir los elementos que confluyen en este tema. Por una parte, comprendemos el cuerpo latinoamericano como una amalgama de innumerables herencias diversas. Por otra parte, entendemos la técnica académica como un elemento homogeneizador que busca, desde sus orígenes, la unificación. Y como un tercer color que tiñe los elementos anteriores encontramos la pedagogía crítica como cuestionador de dicha relación. Todos estos interactúan y se entremezclan bajo el alero de un factor no menos importante: el constante cambio.

\section{Metodología}


Es importante comprender de qué manera se desarrolla el estudio de la danza en Chile. En dicho país existen cuatro universidades que imparten la carrera de danza con salida profesional reconocida por el Ministerio de Educación. El contexto universitario contempla una variedad de personas que ingresan a estudiar danza desde los 18 años en adelante, provenientes de diversos lugares de la ciudad capital, del país, e incluso, de otros países. La enorme diversidad que se puede generar en una sala de clases en la cual se imparta técnica académica considera edad, sexo, procedencia, estudios previos, etc.

El estudio realizado el año 2016 por quien escribe para optar al título de profesora de danza en la Licenciatura en Danza de la Universidad Academia de Humanismo Cristiano contempló una serie de entrevistas a profesores de técnica académica y estudiantes de dicha institución. Estas entrevistas arrojaron un análisis interesante en cuanto a la visión que ambas partes tienen de la técnica. La información recabada se organizó en dos grandes categorías con subcategorías cada una.

\section{Análisis}

La categoría de dificultades de la técnica académica hace especial énfasis a ciertos elementos extraídos de todas las entrevistas que dan cuenta de factores que los entrevistados reconocen dificultan y/o entorpecen el proceso de enseñanza y apropiación de la técnica. Por su parte, el profesor es capaz de reconocer dificultades de dicha técnica, tanto en sus estudiantes, como en su propio aprendizaje de esta. Además, el estudiante reconoce en sí mismo y en su práctica actual los elementos que entorpecen su aprendizaje y el de sus pares para con la técnica académica.

Los resultados arrojan predominancia en la resistencia al concepto ballet y cómo se diferencia de la técnica académica. Existe, por desinformación, la tendencia a creer que la técnica académica se constituye de contenidos muy difíciles, casi imposibles de realizar, puesto que la imagen que se tiene de esta es la del ballet en sí. Dicha concepción establece, a priori, una imprecisión en la comprensión de los objetivos que el estudiante establecerá consigo mismo para con la técnica. Así, desde ese punto de partida, se generará una inevitable resistencia al concepto, puesto que no se comprende desde un comienzo que la técnica, más allá de las destrezas, aporta un dominio transversal a cualquier lenguaje dancístico. Como señala Esteban, el ballet y la técnica académica surgen de un contexto muy similar y mantienen sus caminos cruzados y dependientes entre sí a lo largo de la historia. Sin embargo, esto no significa que en la práctica signifiquen lo mismo (153).

Otro factor importante, relacionado directamente con lo anterior y muy incidente en la investigación, son las dificultades de adherencia y cercanía con la técnica académica de los estudiantes. Dicho término es extraído de uno de los entrevistados, el cual hace referencia a la lejanía que genera la asignatura con los estudiantes. Existe una tendencia a que los estudiantes vean la técnica académica como algo ajeno tanto a sus intereses como a sus proyecciones a futuro. De esta manera, y por lo complejo (a primera vista) de la técnica académica, es que el estudiante genera una distancia con la asignatura. Esta falta de adherencia se traduce en poca presencia del estudiante en clases o baja disposición a trabajar al máximo de sus capacidades y así obtener logros no ocasionales, sino prolongados en el tiempo.

Por consiguiente, se desprende también la exacerbación de las complejidades de la técnica. Parte importante de la distancia que el estudiante establece con dicha técnica va en la visión que tiene de esta. Como ya se ha mencionado, el estudiante tiene tendencia a concebir la técnica académica como un inalcanzable, pues, confunde la imagen estética pulcra y llena de destrezas del 
ballet con lo que se espera alcanzar en clases de técnica académica y genera de manera inmediata una distancia y resistencia. Esto no hace más que desviarlo del objetivo principal de la técnica en el contexto universitario: una herramienta transversal al bailarín. Es muy probable, casi contabilizable en la mayoría de los casos, que el estudiante caiga en una suerte de frustración por no considerar que su proyección de la técnica vaya acorde con sus capacidades.

A estas dificultades podemos sumar, además, la búsqueda de un cuerpo homogéneo en un contexto heterogéneo. Es sabido, pues ha sido mencionado por diversos autores, entre ellos Vergara y Vergara, que Latinoamérica constituye un territorio de amplia diversidad poblacional. Se destaca durante la investigación que el concepto de cuerpo latinoamericano no se sustenta en la singularidad, más bien lo hace en la constante pluralidad, diversidad y variabilidad (Vergara y Vergara 2003). Latinoamérica y Chile no son un tipo de cuerpo, sino muchos tipos de cuerpos en un mismo lugar.

Por otra parte, y en contraposición a esto, la técnica académica en sus orígenes buscó generar un espectáculo que mostrara al espectador un cuerpo perfecto, ingrávido, amplio en destrezas, pero por sobre todo, homogéneo. Por consiguiente, los métodos utilizados desde los inicios de la técnica académica para enseñar los contenidos apuntaron fundamentalmente a crear bailarines de ballet, y consecuentemente, cuerpos muy homogéneos, tanto en aspectos como en capacidades físicas y kinéticas. Con el pasar del tiempo, la técnica se oficializó de esta manera y continuó enseñándose así. Hoy en día, en nuestro contexto, se crea un conflicto al intentar poner en práctica una técnica homogenizadora en un salón de clases en el cual la heterogeneidad es predominante.

La siguiente subcategoría, mencionada también por profesores y estudiantes, aborda el escaso tiempo de estudio de la técnica. Podemos recalcar que la enseñanza de la técnica académica es compleja por todos los factores anteriormente mencionados. A esto se suma que el tiempo de estudio, entiéndase tanto frecuencia de sesiones semanales como tiempo en la planificación curricular, es poco en relación a lo establecido en la técnica desde sus inicios. Si bien las universidades en Chile no buscan formar bailarines de ballet, no existe un replanteamiento metodológico que considere que la técnica no se enseñará en el tiempo estipulado por la metodología base del ballet universal. En ese aspecto, tanto profesores como estudiantes mencionaron que el tiempo de estudio no es suficiente, más aún considerando que al ramo de técnica académica lo acompañan en promedio otros ocho o nueve asignaturas que requieren de la misma atención de parte del estudiant.

Dentro de las subcategorías, se consideran también las acciones corporales propias de la técnica. Por diverso que parezca el tema, es muy posible reconocer que la técnica comprende ciertas dificultades a nivel corporal propias del lenguaje, tales como el dominio de las piernas, la dificultosa acción de rotación externa coxofemoral, o también, más ampliamente, la ligereza y elasticidad tónica del cuerpo. Si bien la mayoría de estas dificultades son reconocibles en la danza en general, su uso en la técnica académica se engloba en un aspecto mucho más detallista y particular de ellas en cuanto a lo que a lenguaje refiere. La labor de sostener dichas dificultades corporales, que van complicándose más a medida de que la técnica se vuelve más avanzada, aumenta muchas veces el distanciamiento de los estudiantes con la técnica académica, quienes desprenden de ello la siguiente subcategoría: los estudiantes tienden a caer en la desconfianza de sus capacidades personales. Todo lo mencionado anteriormente desemboca muchas veces en una incomprensión de la técnica y del objetivo práctico de esta, lo que lleva a frustraciones y dudas de las capacidades propias. Es importante recalcar que el tema de la frustración y los miedos del estudiante en relación a sí mismo dificultan el aprendizaje de la técnica, más en consideración de 
que el estudiante se acompaña, en promedio, de veinticinco compañeros más que pueden pasar por lo mismo en momentos distintos o iguales a él/ella.

Respecto de lo anteior, los datos recopilados en las entrevistas dieron pie a la conformación de la siguiente categoría, que hace referencia a las estrategias pedagógicas incidentes en el proceso de enseñanza y aprendizaje de la técnica académica. Por su parte, y al ahondar en las subcategorías dentro de las estrategias pedagógicas, los profesores destacan en su labor diaria que la cercanía del profesor con los estudiantes es un factor determinante para comprender el proceso pedagógico y obtener resultados de ello. Si analizamos esto desde el punto de vista de Paulo Freire, tendremos presente la noción del profesor como ente regulador del conocimiento, no como alguien que impone un determinado contenido. De esta manera, la pedagogía se transforma en un diálogo que permite que tanto el estudiante como el profesor comprendan e incorporen nuevos elementos a su experiencia, lo que invita al profesor a ir construyendo su método pedagógico a partir de las necesidades prácticas que van surgiendo del estudiante y el quehacer educativo. A partir de esto, se infiere la siguiente subcategoría que se relaciona con que en dicha interacción suceden métodos pedagógicos adaptables a las necesidades específicas del grupo/persona en cuestión. Sin duda, las necesidades de un grupo universitario de danza no son las mismas que un grupo de estudiantes de técnica académica orientados al ballet, pues, como ya se ha mencionado anteriormente, ambos contextos son muy diferentes.

Es recomendable que tanto profesor como estudiante trabajen juntos en la tarea de que ambos, pero especialmente este último, sean capaces de reconocer los objetivos del curso tanto a nivel de micro y macro objetivos, según lo planteado por McLaren. De esta manera, el estudiante es capaz de generar el nexo indicado que potenciará a la técnica académica como una herramienta transversal a sus estudios y desarrollo profesional, de forma que dichos aprendizajes no queden abandonados de la puerta de la sala de clases hacia adentro.

$\mathrm{Al}$ respecto, es importante generar la unión también con el material teórico existente en la técnica académica, pues a lo largo de la historia se han creado numerosos escritos acerca de la metodología de enseñanza de esta. Es fundamental ser capaces, tal como Gómez y Gómez lo mencionan en su noción de pedagogía crítica, de complementar la teoría con la práctica y viceversa, a fin de generar un vínculo sólido entre la realidad y la reflexión (82). La técnica académica, a pesar de ser fundamentalmente práctica, se sustenta sobre una importante base teórica que, en medida que sea aplicable a las necesidades del estudiantado y comprendida como elemento flexible, puede sustentar un surgir metodológico muy acorde a las particularidades del universitario en danza.

Queda en claro, según lo expuesto por los estudiantes en sus entrevistas, que la resolución de dudas durante la clase significa un factor fundamental a la hora de la comprensión del suceso pedagógico. Al respecto, el desafío para el profesor es de alta complejidad, pues comprende el conocimiento tanto de la teoría como de la práctica para tener la capacidad de reacción inmediata in situ y así responder de manera inmediata en función del acontecer en clase. Así, el enfoque pedagógico de una clase se humaniza y dista mucho del parámetro instructivo que Roberto Ramírez menciona (111).

Parte fundamental de esta investigación, y a la cual hacen referencia los estudiantes desde su mirada en la práctica, es el enfoque pedagógico de la relación técnica/ cuerpo. Frente al tema de conversación de si la técnica debe modificarse en función del cuerpo, o el cuerpo debe modificarse en función de la técnica, en las respuestas se vuelve evidente que la técnica y sus metodologías deben representar un factor modificable en la práctica, a fin de des-rigidizar su ejercicio y enriquecer día a día su labor de herramienta transversal útil para todo lenguaje. 


\section{Conclusiones}

Existe de parte de las nuevas generaciones, hoy en el siglo XXI, una inquietud constante de cuestionar los ejes que cruzan su vida. Su constante cuestionamiento social no deja exenta al área de la enseñanza, pues se busca hoy en día de manera persistente, como hemos visto con variados autores, la mejora de la educación en favor de la humanización y la particularidad del individuo como ente único e irrepetible. Al respecto, la danza no constituye un elemento aparte, tanto del acontecer social, como del acontecer educacional. Queda al descubierto en el material recaudado que el debate en relación con la pedagogía no deja indiferente a nadie, ni nada, mucho menos a una técnica que ha recorrido siglos en su desarrollo e investigación. La danza, como ya se ha mencionado, ha sido y continúa siendo, un elemento representativo del acontecer humano, del suceso emocional y subjetivo de mujeres, hombres y demases. Su puesta en marcha considera un eje transversal a la humanidad en todas sus etapas y contextos: la expresión. Es, por tanto, un componente fundamental en lo que a manifestaciones humanas respecta. Si entendemos la manifestación como la declaración de un parecer frente a uno o más temas específicos en todo aspecto humano. Como tal, es importante notar la necesidad de que la técnica académica, en tanto manifestación artística humana, sea también un elemento maleable de acuerdo al contexto, y transite de la mano junto a la diversidad, no rehuyendo de ella.

A partir de la pregunta que da pie a la investigación realizada el año 2016 por la autora, es posible afirmar que los datos recabados sí responden a los objetivos enunciados en esta. Pues, a través de las observaciones y entrevistas realizadas, se puede dar cuenta de que en las salas de clases se está abordando el conflicto sociocorporal homogenizante que reproduce la técnica académica y se le da un vuelco hacia la concientización y modificación de metodologías en pro de la diversidad corporal que habita las aulas de danza en latinoamérica.

Es posible decantar la información obtenida en una serie de conclusiones que se expondrán a continuación y que propician este tránsito desde lo homogéneo a la diversidad en la técnica académica.

El primer punto, y fundamental a la hora de trazar las líneas de lo extraído de la investigación, es la noción de la técnica académica como herramienta. Se esclarece constantemente en clases que la técnica es un elemento transversal a la práctica dancística, en tanto ocupación (pedagogía, interpretación, coreografía, etc.) y lenguajes. El profesional de la danza, sea en el área que sea que oriente su trabajo, y sea cual sea el lenguaje que considere afín, puede nutrir su práctica de manera más completa al tener en sus dominios una buena base de técnica académica. Y es importante también recalcar que este planteamiento desecha/cuestiona el tema de las destrezas, pues se comprende el manejo técnico como la sólida y certera ejecución de la técnica, no en el engrandecimiento de destrezas o pericias.

Es importante también ahondar en la pedagogía a través del énfasis constructivista, pues con la adecuada orientación del docente, los estudiantes pueden ser capaces de construir conocimiento consigo mismos, junto a su entorno y los otros. Específicamente en técnica académica, esto nos habla de la capacidad del estudiante de generar vínculos entre lo que está incorporando como aprendizaje, y cómo esto puede ser aplicable en su práctica dancística general. 
De esta manera, la técnica académica deja de ser un elemento aislado del currículum y pasa a nutrirse de otras materias y a la vez a constituir un apoyo a estas.

Para ello, la labor del docente se orienta hacia la comprensión de las metodologías de la técnica académica como flexibles, sujetas a ciertas variaciones de acuerdo a las necesidades que este reconozca en sus estudiantes. Si el profesor comprende el suceso pedagógico como una construcción mutua, será capaz de responder a estas necesidades y complementar los planes de estudios con lo que en la práctica va elevando como necesidad. De esta manera, e inevitablemente, las metodologías deberán adecuarse al acontecer en práctica, y por ende, modificarse en función de ello.

A través de la comprensión del cuerpo latinoamericano como confluencia de la diversidad corpóreo-identitaria, es posible generar un nexo con la técnica académica y la pedagogía desde el punto de vista del cuestionamiento. Es esta última la que durante la investigación pone en cuestión ambas partes, por un lado al buscar comprender cómo reaccionan los cuerpos diversos frente a una técnica implementada de manera rígida, y por otro lado, al ver de qué manera esta técnica puede llegar a ser, sin perderse en el camino, una mejor herramienta para el bailarín. Entonces, se puede concluir que las estrategias a las que recurren profesores y estudiantes en técnica académica orientadas al cuerpo latinoamericano responden fundamentalmente, y muy a grandes rasgos, a la modificación de las metodologías en función de la diversidad.

Esta información recaudada nos da cuenta de un acontecer que no podrá más que nutrirse de cercanía, pues si todas estas conclusiones se ponen en práctica, el salón de clases de técnica académica constituirá un contexto amable, humano en su pedagogía y lleno de frutos en construcción mutua entre estudiantes y profesores. De ser así, se vuelve posible relacionar la investigación con un elemento transversal a ella: la resistencia y el arte como elemento político. Se vuelve de vital importancia mencionar este tema, puesto que el contexto diverso de nuestro continente abarca ineludiblemente lo político en todos sus ámbitos. Así, debemos entonces concientizar y profundizar en que la modificación de la metodología de la técnica académica comprende una acción política, pues esto constituye un factor de resistencia histórica, social y política. A través del cuestionamiento y la proposición de una mirada relacionada a la realidad en las aulas, es que la técnica académica puede abordarse desde un punto de vista más ameno y acorde a lo que como cuerpo diverso somos en la danza, lo que lleva a contemplar la tradición como un elemento capaz de evolucionar en pro de las necesidades y el acontecer histórico. Dicha evolución comprenderá en su esencia un hecho político. 


\section{Bibliografía}

Abad, Javier. Usos y funciones de las artes en la educación y el desarrollo humano. Madrid, España: Fundación Santillana, 2009. Impreso.

Adame, Domingo. Elogio del oxímoron. Introducción a las teorías de la teatralidad. Ciudad de México, México: Ed. Universidad Veracruzana, 2005. Impreso.

Díez del Corral, Pilar. "Una nueva mirada a la educación artística desde el paradigma del desarrollo humano". Tesis Universidad Complutense de Madrid, Facultad de Bellas Artes, 2005. Impreso.

Esteban, Nieves. Ballet, Nacimiento de un arte. Madrid, España: Editorial Librerías Deportivas, 1993. Impreso.

Freire, Paulo. Pedagogía de la autonomía. Saberes necesarios para la práctica educativa. Buenos Aires, Argentina: Siglo XXI editores, 1996. Impreso.

García Canclini, Néstor. Culturas Híbridas. BuenosAires, Argentina: Editorial Paidós. 1990. Impreso.

Gómez, Juan y Luis Gómez. "Elementos teóricos y prácticos de la pedagogía crítica: Más allá de la educación, metáfora, escena y experiencia". Revista PRAXIS 66 (2011): s.p. Web. 14 Oct. 2017.

González, Luis. "La pedagogía crítica de Henry A. Giroux”. Revista Electrónica Sinéctica 29 (2006): s.p. Web. 16 Sept. 2017.

McLaren, Peter. La vida en las escuelas. Una introducción a la pedagogía crítica en los fundamentos de la educación. México: Siglo XXI Editores. 1984. Impreso.

Mora, Ana. "El aprendizaje de la danza en un campo de creencia y de luchas. La perspectiva analítica de Pierre Bourdieu y su contribución a la antropología de la danza". Revista Maguaré 12 (2007): s.p. Web. 1 Sept. 2017.

Pedraza, Zandra. "Conocimiento, experiencia y condición humana". Revista Colombiana de Antropología 45 (2009): s.p. Web. 15 Nov. 2018.

Ramírez, Roberto. "La Pedagogía Crítica. Una manera ética de generar procesos educativos". Revista Folios 28 (2008): s.p. Web. 18 Nov. 2018.

Silva, Osvaldo. Civilizaciones prehispánicas de América. Santiago, Chile: Editorial Universitaria. 2006. Impreso.

Vergara, Jorge y Jorge Vergara del Solar. "Cuatro tesis sobre la identidad cultural latinoamericana. Una reflexión sociológica”. Revista de Ciencias Sociales 12 (2002): s.p. Web. 18 Dic. 2017.

Recibido: 01 de Abril de 2020

Aceptado: 21 de Diciembre de 2020 